\title{
Modelling Across the Process Life Cycle: A Risk Management Perspective
}

\author{
Ian T Cameron \\ School of Engineering \\ The University of Queensland, Brisbane, Australia 4072
}

\begin{abstract}
The process life cycle is a well established concept, having increasingly become a corporate and regulatory imperative. Motivated by a history of major commercial, environmental and societal failures or disasters, the product and process life cycle is underscored by the application of risk management principles. Decision making, driven principally by considerations of a wide range of risks provides the context for the modelling that occurs across the life cycle, especially that for product and process.

This paper illustrates, analyses and discusses the role of modelling within the multidisciplinary life cycle framework, emphasising the centrality of the process issues and the growing need of the process engineering community to look beyond the confines of process engineering. The paper considers the application of risk management principles to the modelling life cycle, highlighting some of the unfulfilled challenges in this area.
\end{abstract}

Keywords: life cycle, modelling, risk management, multidisciplinary

\section{Introduction}

It was the mid 1960s and one of the world's leading chemical companies had just designed and installed a new, expensive heat integrated reactor system. Commissioning was underway but the system behaviour was so erratic as to make the process inoperable. The solution? - modelling the system on the company's large analogue computer to find just why it oscillated so badly. A solution was found and implemented - an early example of the power of dynamic modelling (Anderson 1966). This story, related to me years later, was my introduction as a new company supported PhD student to the brave new world of dynamic modelling! It is also a lesson that effective risk management could have been exercised through prior and appropriate modelling in order to avoid the problem. Do similar incidents occur today? - absolutely; so what challenges does this 40 year old incident reflect and what role does modelling play across the life cycle? We investigate some of the issues in the following sections.

The life cycle concept is hardly new. It has been a part of all civilizations from prehistory. Its current appeal is in the formalization and application of the ideas to a wide range of commercial, industrial and environmental practices. 
Likewise the ideas of risk management have a long established history and towards the end of the $20^{\text {th }}$ century process risk management practice became formalized across the world through significant legislation, regulations (OSHA 1992; EC 1996; NOHSC 1996; COMAH 1999; SA 2004).

For the $21^{\text {st }}$ century, the life cycle (LC) idea has taken on a growing importance for all human activities, driven by concerns for sustainability, global warming, safety, health and environmental issues. In many cases life cycle concepts are at the heart of the sustainability of whole communities, economic regions or countries. Much of this attention to life cycle assessment (LCA) has been driven by government, community and industrial concerns arising from acute impacts of fires, explosions and toxic releases or through more sinister chronic impacts affecting people and the biosphere. (Carson 1962; Perrow 1999; Chiles 2001; Crichton 2004; Gäbel et al. 2004).

The intimate meshing of life cycle approaches and risk management is evident in the most recent LC standards and legislation throughout Europe, North America and Australasia (ISO 2002; SA 2003). With LCA and risk management processes becoming closely intertwined in most commercial, industrial and societal issues, the tools necessary to support decision making at all phases have become increasingly important.

Of overwhelming importance is the growing use of modelling within the life cycle phases. This use has been fuelled by massive increases in computing resources, available data, access to increasingly wide range of analysis approaches driven by deeper insights into basic physics, chemistry as well as a growing understanding of the complex interactions of systems. Figure 1 shows the key concepts and their interplay. Amongst the LC systems of interest to process engineering are economics and finance, other engineering disciplines, marketing, health, environment, biology and society.

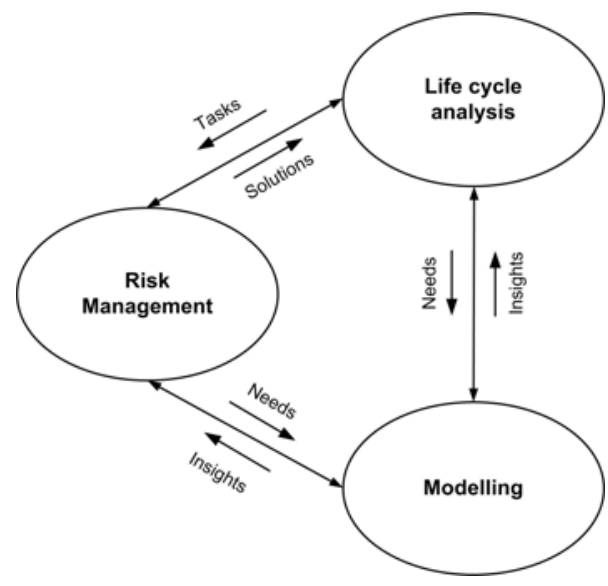

Figure 1 Key relationships amongst LCA, RM and Modelling

The important point to make here is that LC approaches are both multidisciplinary and interdisciplinary - a fact that impacts significantly on how we use modelling across the product and process life cycle. Some of these issues have been addressed from the specific context of process modelling by Marquardt et al. (2000) and Virkki-Hatakka et 
al. (2003). Recent reviews by Britt et al. (2004) and Pantelides \& Urban (2004) give further details from the industrial and vendors' perspectives on process related modelling.

The focus in this paper is to draw together the three strands of life cycle concepts, risk management and modern modelling practice to consider the importance, status, and future of modelling as a decision making tool - most often addressing risk issues for 'cradle-to-grave' product and process engineering. Modelling is clearly the servant and not the master and there are also significant risk management issues for modelling practice across the life cycle.

Hence, the views and outcomes expressed here are driven by the fact that there are two principal life cycles that are running - the product/process life cycle AND the model life cycle. Both are considered to get a full appreciation of their importance.

\section{Life Cycle Concepts and Issues}

In the area of systems engineering, life cycle concepts have been expressed in numerous international standards such as the ISO14000 series and ISO15288 (ISO 2002). The generic life cycle stages in these standards involve:

- concept - analyzing needs, identifying key concepts, developing potential solutions

- development - engineering a product and process

- production - manufacturing the product

- utilization - operating or using the product

- support - maintaining and supporting the product and process

- retirement - retiring, disposing or archiving the product and process

These concepts are now central in the process and manufacturing industries, driven by tough environmental impact assessment regimes that demand in-depth analysis of the socio-technical aspects of all major developments as well as facility expansions - well before any implementation. The Responsible $\mathrm{Care}^{\mathrm{TM}}$ program of the International Council of Chemical Associations had LCA as a part of its implementation since 1988 (ICCA 2004). The whole area of product conception, development and use is now being increasingly driven by principles and application of product life cycle management (PLM). Integrated PLM vision strategies and planning have the potential in some cases to double productivity, reduce development cycle times by $80 \%$ and product cost by $40 \%$ (Stark 2005).

Life cycle assessment sits in a broader socio-technical context beyond the mere productprocess perspective. In this way, the life cycle concept is seen as a much more holistic focus.

\subsection{The process life cycle perspective}

The process life cycle is clearly a related concept. It is characterized by a number of sequential stages as shown in Figure 2. These stages are contrasted to the generic phases of ISO15288. Accompanying the process life cycle phases are key activities 
associated with each phase. Of prime importance throughout the life cycle perspective are the issues of raw materials, wastes and emissions, energy consumption, generation and re-use. These issues are necessarily part of a truly integrated framework (Rosselot et al. 2002).

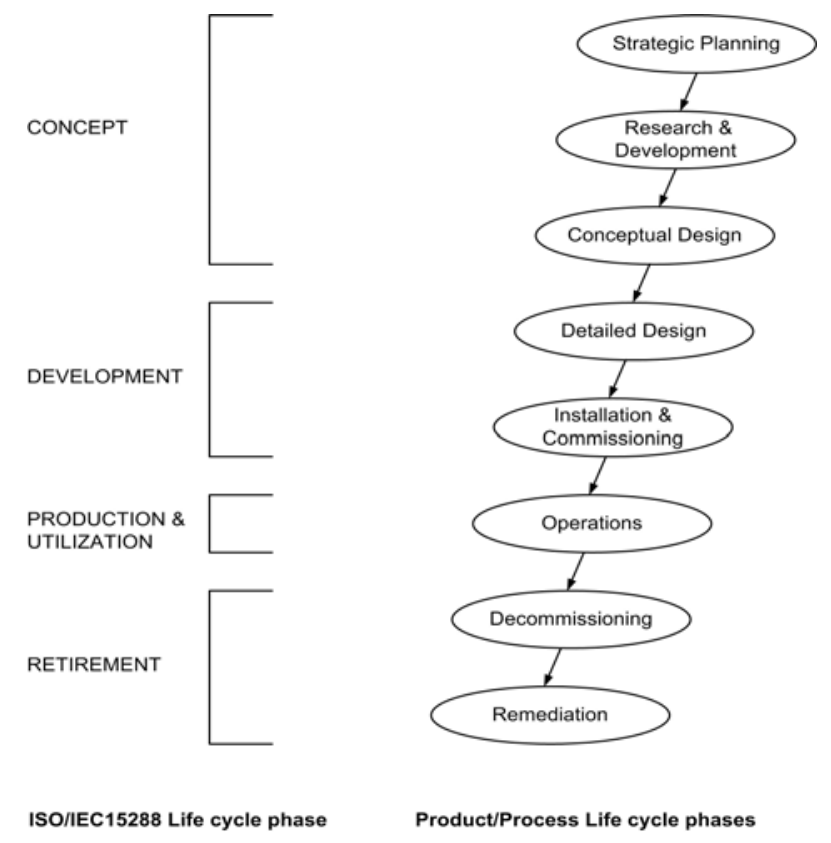

Figure 2 Life cycle phases - generic and product/process related

Some of the individual activities or considerations of the life cycle phases illustrate the many applications areas:

- strategic planning:

- initial ideas of resource utilization or new product development and innovation

- new business opportunities, potential markets, production locations

- synergies with other commercial/industrial ventures

- research and development activities:

- synthesizing new substances, drugs or products

- market responses to product ideas

- fundamental reaction pathways, kinetics and conditions

- energy and utilities utilization for product creation

- development and validation of key physico-chemical and toxicological properties

- conceptual design of product and process:

- alternate production routes and process materials

- economic potential and financial assessments

- potential environmental impacts and early risk assessments

- $\quad$ strategies for retirement and decommissioning

- detailed engineering designs:

- definitive engineering flow sheets and PIDs 
- importance of dynamics, operability and flexibility

- control system structures and optimal operation

- embedded software verification

- layered protection designs

- ergonomic and human-machine interface designs

- hazard analysis and risk estimation

- procurement strategies

- installation and commissioning:

- construction management and critical path analysis

- resource allocation and logistics

- pre-commissioning, startup sequencing and system verification

- operations and production:

- maintenance philosophies and strategic planning

- emergency response and risk management

- supply chain design, optimization and operation

- process de-bottlenecking and evolutionary product/process improvement

- environmental management plans (EMPs)

- decommissioning of process:

- decontamination and disposal options

- recycling and salvage opportunities

- remediation of process related facilities:

- environmental and amenity aspects

- future land uses and planning issues

Evident from such a brief list is the fact that life cycle activities involve a broad range of disparate disciplines. This broad base of disciplines necessarily links directly into the product and process design activities of the life cycle requiring strategic data and information to enable the wide range of decision making to take place. Hicks et al. (2000) describe design processes that consider process decommissioning at the concept stage indicating the necessary corporate commitment for such activities. A key recognition is that the product and process activities provide the "backbone" to associated activities such as economics, finance, human factors and society. In all these activities, risk management plays a central role.

\subsection{Life cycle risk management issues}

In general terms, "risk" is the existence of uncertainty about future outcomes. More formal technical definitions are also used in risk management practice (Cameron \& Raman 2005), the most common being: "The likelihood of a specific level of harm being realized in a specific time or under specific circumstances".

Risk most frequently addresses adverse outcomes but is equally used to address beneficial outcomes for business innovation (Kwak \& LaPlace 2005). Managing risk is managing uncertainty and the risk management process is central to the life cycle.

The ISO/IEC15288:2002 standard calls for a risk management process as part of system life cycle management. It is applied to each stage of the system life cycle as illustrated in Figure 3. 


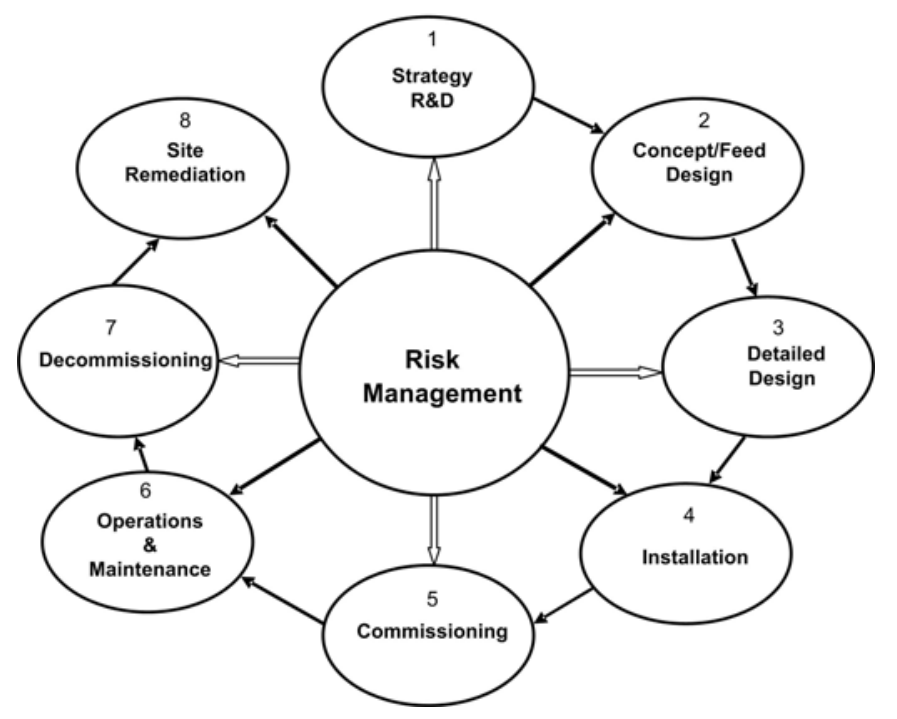

Figure 3 The interaction of risk management with the product/process life cycle

The key, basic elements of a risk management approach are: identification, estimation, assessment and treatment of risks. Of primary importance are the dimensions of risk which focus on risk receptors. Figure 4 shows some common risk dimensions relevant to commercial, industrial and societal receptors.
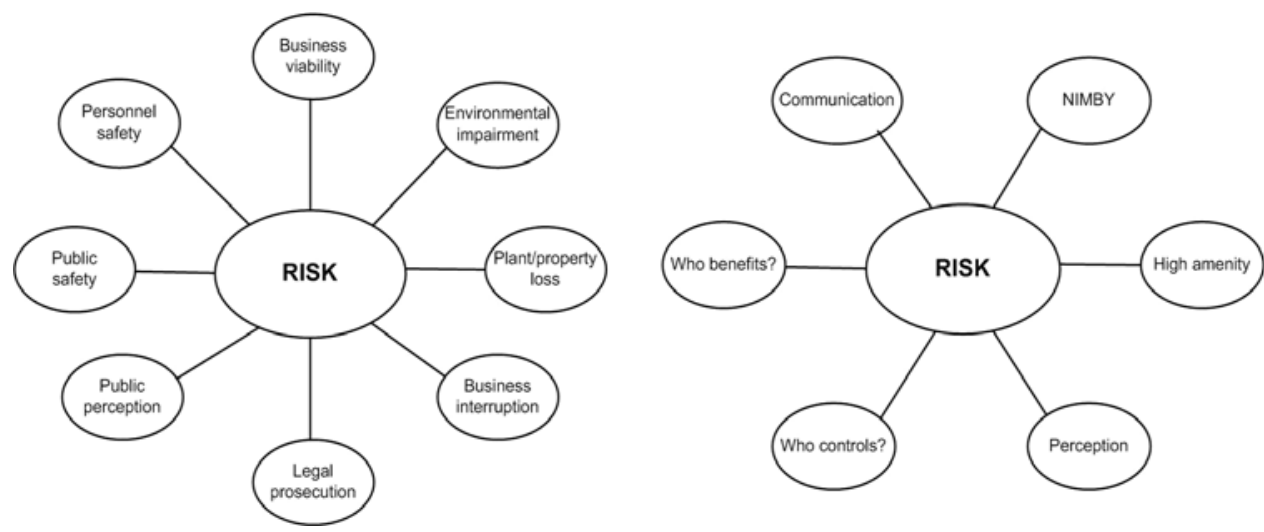

Figure 4 Some dimensions of risk for commerce, industry and society

Table 1 gives a selected set of typical risk management tasks across the life cycle phases. This table clearly shows that within the process life cycle, risk management practice spans all aspects of the product and process as well as economic, financial, human, environmental, societal and regulatory regimes. It is a central activity that generates the primary links between the product/process engineering community and many other professions and communities. 
Table 1 Selected Life Cycle Risk Management Tasks

\begin{tabular}{|c|c|}
\hline Life Cycle Phase & Selected Risk Management Tasks \\
\hline Strategic planning & $\begin{array}{l}\text { - business innovation for competitive advantage } \\
\text { - company viability in changing product markets } \\
\text { - short, medium and long term business development } \\
\text { - mergers, takeovers and alliances }\end{array}$ \\
\hline Research and development & $\begin{array}{l}\text { - effective employment of inherently safer designs } \\
\text { - high level hazard identification } \\
\text { - adequate knowledge of toxicology, impairment factors } \\
\text { - reliability/adequacy of physico-chemical properties } \\
\text { - identify and manage human error }\end{array}$ \\
\hline Conceptual design & $\begin{array}{l}\text { - optimal production routes } \\
\text { - inherently safer design (ISD) hierarchies } \\
\text { - hazard identification } \\
\text { - selection of solvents, separation agents } \\
\text { - ensuring economic viability from the design } \\
\text { - assessing key environmental impacts } \\
\text { - identify and manage human error }\end{array}$ \\
\hline Detailed design & $\begin{array}{l}\text { - ensuring equipment integrity and performance } \\
\text { - optimal equipment design and selection } \\
\text { - safety critical systems performance } \\
\text { - comprehensive hazard identification } \\
\text { - environmental performance } \\
\text { - loss prevention design, integrating safety analysis } \\
\text { - life cycle cost analysis } \\
\text { - system availability analysis to confirm design availability } \\
\text { - effective management of change procedures } \\
\text { - identification and management of human error } \\
\text { - constructability issues and interfaces with design } \\
\text { - de-commissioning issues in design } \\
\text { - interaction of coupled operations }\end{array}$ \\
\hline $\begin{array}{l}\text { Construction, installation } \\
\text { and commissioning }\end{array}$ & $\begin{array}{l}\text { - equipment "fit for purpose” at fabrication stage } \\
\text { - ensuring critical path construction processes } \\
\text { - construction safety management plan and implementation } \\
\text { - application of relevant SMS elements } \\
\text { - management of simultaneous operations } \\
\text { - management of interface safety issues } \\
\text { - identification of commissioning hazards } \\
\text { - identification and management of human error } \\
\text { - implementation of Environmental Management System }\end{array}$ \\
\hline Operations and & - operator effectiveness \\
\hline Maintenance (O\&M) & $\begin{array}{l}\text { - abnormal situation management } \\
\text { - emergency response planning } \\
\text { - SMS performance monitoring } \\
\text { - process safety auditing and management feedback } \\
\text { - Reliability Centred Maintenance (RCM) } \\
\text { - real-time optimization } \\
\text { - efficient supply chain operations } \\
\text { - opportunities for risk reduction } \\
\text { - identification and management of human error }\end{array}$ \\
\hline
\end{tabular}




\begin{tabular}{ll}
\hline Life Cycle Phase & Selected Risk Management Tasks \\
\hline Decommissioning & - decommissioning strategies \\
& - decontamination safety review \\
\hline Remediation and retirement & - site testing and assessment \\
& - environmental remediation plan \\
\hline
\end{tabular}

One key implication is that the outcomes of product and process engineering decisions provide the backbone to a multi- and interdisciplinary life cycle system. The decision making processes within product and process engineering are largely informed and driven through a wide range of modelling. The focus of nearly all modelling is decision making that informs technical choices that ultimately address underlying risk issues.

For example, the withdrawal in 1998 by Roche of the hypertension and angina drug Posicor, just 10 months after launch, was accompanied by significant financial losses and litigation. This was due to unforeseen drug-drug interactions - one of many such incidents across the new drug sector (Hodgson 2001). The growing use of ADMET 'in silico' molecular and structural chemistry modelling is now seen as an important tool to assess drug interactions and toxicology, thus helping to reduce major financial and legal risks for drug companies as well as enhancing drug efficacy. With new drug development costs in the range of \$US300-800 million, impact of failure is significant (Rawlins 2004). The following section investigates the diversity of life cycle modelling, necessary for a large commercial/industrial operation.

\section{Modelling Across the Life Cycle}

\subsection{Model form and application}

In the areas of commercial and industrial product/process development or in project impact assessment under regulatory requirements, the breadth and depth of modelling needed for decision making is obvious. Some of the modelling applications, modelling forms and approaches across the process life cycle are given in Table 2.

Table 2 Selected model use and characteristics in the process life cycle

\begin{tabular}{|c|c|c|}
\hline Process Life cycle phase & Modelling applications & $\begin{array}{l}\text { Modelling forms, tools and } \\
\text { approaches }\end{array}$ \\
\hline Strategic planning & $\begin{array}{l}\text { - Market potential. } \\
\text { - Finance and economics. } \\
\text { - Resource assessment. }\end{array}$ & $\begin{array}{l}\text { - Purpose, goal, mission models. } \\
\text { - Issue based planning models } \\
\text { - Scenario models. } \\
\text { - Self-organizing models. }\end{array}$ \\
\hline Research \& Development & $\begin{array}{l}\text { - Resource characterization. } \\
\text { - Basic chemistry, toxicology. } \\
\text { - Reaction kinetics. } \\
\text { - Catalyst activity life. } \\
\text { - Physico-chemical behaviour. } \\
\text { - Pilot plant design and } \\
\text { operation. }\end{array}$ & $\begin{array}{l}\text { - Reaction network models. } \\
\text { - Catalysis models. } \\
\text { - PFR, CSTR reactor models. } \\
\text { - Elementary flowsheet models. } \\
\text { - Fluid-phase equilibria models. } \\
\text { - Physical property models. } \\
\text { - Molecular simulation } \\
\text { - Quantum chemistry models. }\end{array}$ \\
\hline Conceptual design & - Preliminary mass \& energy & - Flowsheeting packages. \\
\hline
\end{tabular}




\begin{tabular}{|c|c|c|}
\hline & $\begin{array}{l}\text { balances } \\
\text { - Alternate reaction routes } \\
\text { - Alternate process routes } \\
\text { - Input-output economic } \\
\text { analysis } \\
\text { - Preliminary risk assessment - } \\
\text { - Plant/site water balances. } \\
\text { - Initial environmental impact. } \\
\text { - Detailed risk assessment. } \\
\text { - Economic analysis }\end{array}$ & $\begin{array}{l}\text { - Semi-quantitative risk models } \\
\text { - Financial analysis models } \\
\text { - Environmental impact models } \\
\text { (air, noise, water, solid wastes). } \\
\text { - Social impact assessment models. } \\
\text { - Consequence, frequency and risk } \\
\text { models. } \\
\text { - Computational fluid dynamics } \\
\text { - Risk outrage prediction }\end{array}$ \\
\hline Detailed design & $\begin{array}{l}\text { - Detailed mass \& energy } \\
\text { balances. } \\
\text { - Vessel design and } \\
\text { specifications. } \\
\text { - Control systems design and } \\
\text { assessment } \\
\text { - Socio-technical risk } \\
\text { assessment. } \\
\text { - Emergency planning } \\
\text { - Project management } \\
\text { - Environment }\end{array}$ & $\begin{array}{l}\text { - Flowsheeting packages. } \\
\text { - Dynamic simulation for plant } \\
\text { units and control design. } \\
\text { - Grafcet and ladder logic models. } \\
\text { - Hybrid system models } \\
\text { - CFD modeling and simulation. } \\
\text { - Mechanical simulation (FEM). } \\
\text { - 3D plant layout models. } \\
\text { - Fire, explosion, toxic release } \\
\text { models. } \\
\text { - Ground water prediction models } \\
\text { - Fault tree and event tree models } \\
\text { - Air-shed models for dispersion of } \\
\text { gases and particulates. } \\
\text { - Noise level models. }\end{array}$ \\
\hline Commissioning & $\begin{array}{l}\text { - Startup procedures. } \\
\text { - Shutdown procedures. } \\
\text { - Emergency response. }\end{array}$ & $\begin{array}{l}\text { - Safety instrumented assessment } \\
\text { models. } \\
\text { - Risk assessment models. }\end{array}$ \\
\hline $\begin{array}{l}\text { Operations \& } \\
\text { Maintenance }\end{array}$ & $\begin{array}{l}\text { - Process optimization. } \\
\text { - Process batch scheduling. } \\
\text { - Supply chain design and } \\
\text { optimization. }\end{array}$ & $\begin{array}{l}\text { - Scheduling models. } \\
\text { - Unit and plant wide optimization } \\
\text { models (LP, NLP, MILP, MINLP). } \\
\text { - Optimal control models. } \\
\text { - SCOR models for supply chains } \\
\text { - Operator training systems } \\
\text { - Real-time expert system models. } \\
\text { - Neural nets and variants. } \\
\text { - Empirical models (ARMAX, BJ). } \\
\text { - Maintenance models (RCM). }\end{array}$ \\
\hline Retrofit & $\begin{array}{l}\text { - Debottle-necking studies. } \\
\text { - Redesign. }\end{array}$ & $\begin{array}{l}\text { - Flowsheeting packages. } \\
\text { - Detailed dynamic models. } \\
\text { - Computational fluid dynamics }\end{array}$ \\
\hline Decommissioning & $\begin{array}{l}\text { - Disposal processes and } \\
\text { strategies. } \\
\text { - Decontamination of } \\
\text { equipment }\end{array}$ & $\begin{array}{l}\text { - Specialized models for the } \\
\text { processes involved (incineration, } \\
\text { ozonation etc.) } \\
\text { - Critical path scheduling systems }\end{array}$ \\
\hline $\begin{array}{l}\text { Remediation and } \\
\text { restoration }\end{array}$ & $\begin{array}{l}\text { - Geotechnical. } \\
\text { - Contaminant extraction } \\
\text { options. }\end{array}$ & $\begin{array}{l}\text { - 4D physical extraction models. } \\
\text { - Soil processing models for } \\
\text { decontamination. }\end{array}$ \\
\hline
\end{tabular}


Table 2 illustrates the diversity of modelling activities throughout the life cycle. There are many forms and approaches used in the life cycle phases, with significant re-use of core modelling components or integration of core process models with wider sociotechnical applications. This presents a number of challenges to organizations using modelling as a key business and technical decision tool.

\subsection{Model Management Issues}

It is important to note that for an organization developing products and processes a number of potentially important interactions occur during the life cycle that will be the focus of risk management practices. These include:

- The assignment of responsibilities for the core process activities that involve the development of process models, flowsheets, related control and operational strategies, optimization and financial assessments. Many of these activities are now "outsourced" to major engineering and financial consultancies due to corporate focus on "core business". Other activities such as control and operational strategies are often retained in-house. This practice has accelerated rapidly over the last 20 years with the demise of many major in-house engineering and design groups in large multinational organizations. This places particular risk management challenges on organizations where engineering consultancies and vendors merge, disappear, change focus or have very different corporate cultures from the operating company.

These external links create opportunities for increased risk in the development, use and deployment of models and accompanying decision making. These links need to be handled well to minimize adverse impacts. Collaborative development environments and strategic partnerships between service providers and production companies are now commonplace with a merging of standards, practices and cultures. Britt et al. (2004) comment briefly on this aspect in relation to particular architectures of collaboration that can be adopted. Their emphasis is on information access and handling.

- The development and evolution of the product and process across the complete life cycle means that model management becomes a significant task. With typical process life being 25 or more years for major developments, the modelling efforts at the concept, design and operational phases require longevity. Given the dynamic nature of business and regulatory environments, model management from a risk perspective is vitally important. Areas of focus include knowledge capture and retention, audit trails for model building, design and operational decisions; change in model building environments, changes in corporate and consultancy staff and personnel.

The next section briefly deals with a number of these issues and highlights the challenges still facing developers and users of modelling across the life cycle. 


\section{Modelling, risk and the life cycles}

The areas addressed here relate to risk issues for modelling use across the process life cycle and the risk issues surrounding the core process modelling life cycle. The first addresses the external or interface issues of modelling applications that rely on the underlying process modelling. The second area focuses on issues for the development, use and maintenance of the core process modelling. Both need to be considered within the context of corporate risk management practice.

Table 2 showed a wide range of characteristics in current modelling practice. There have been a number of excellent recent reviews on various aspects of process modelling including Marquardt et al. (2000), Pantelides (2001), Britt et al. (2004) and Pantelides \& Urban (2004). The reader is referred to these papers for the details. Across the life cycle some key modelling characteristics and related risk management issues include:

- A diversity of modelling goals.

Here the risk management issues relate to the generation of "fit-for-purpose" models. Current industrial modelling practice does not generally follow a systematic and goal driven approach to model development. This is despite the key place that modelling goals play in the modelling cycle seen in Figure 5.

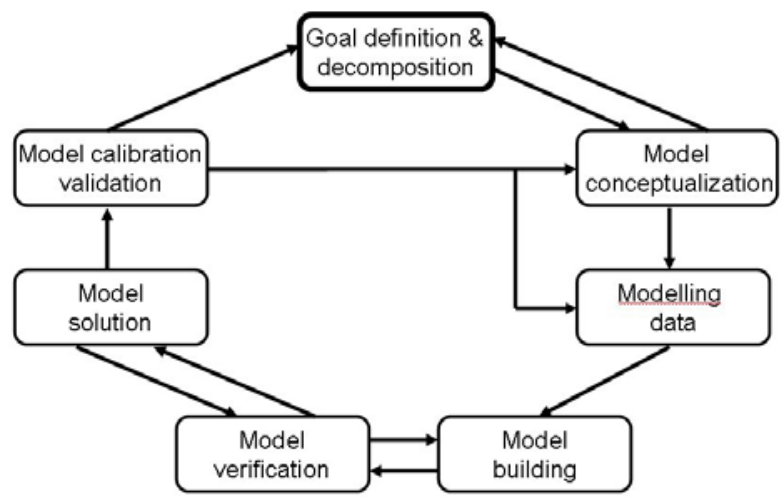

Figure 5 The modelling cycle

Models often take too much time to develop, are too complex or too simplistic for their intended end use. The risk is that the models are not fit for the job with subsequent reengineering required. Managing this issue requires new formalized methodologies and accompanying tools that allow developers to clearly define modelling goals and performance criteria in such a way that the attainment of goals can be monitored and achieved in a parsimonious fashion. This approach is in its infancy. Pantelides \& Urban (2004), suggest that such methodological changes are very difficult to address in commercial software environments. Adoption of new methodologies often starts in education and training environments and this is a matter for educators.

This goal setting aspect of process modelling is generally poorly done but is essential for establishing the termination conditions for the modeling cycle. It still remains a 
complex, difficult area with little guidance or techniques in how overall or canonical goals are decomposed into sub-goals as represented in a goal-tree or goal-graph and then subsequently to define the subsystems. The other area that requires significant improvement is the conceptualization phase. Higher level modelling that works with descriptions at the phenomenological level can provide a partial solution but have lacked adoption by users (Stephanopoulos et al. 1990, Williams et al. 2002). This requires further development and promotion in industrial environments.

There is clearly a significant appeal in the concept of a single consistent process model. However, in practice, a family of inter-related models is normally developed because of the modelling goals being addressed (McGahey \& Cameron 2002). There is the risk that the relationships between models is not well documented or clearly understood by the developer and the user, leading to inappropriate use for decision making. Documentation systems such as IBIS (Bañares-Alcantará et al. 1995, Bogusch et al. 1996) have been suggested but have not found wide application - possibly due to the demands required in text based systems. The author has found that the use of .mp3 recorders provided an alternate means of documenting decisions in the generation of fault tree and event tree models for environmental risk assessment. These were subsequently attached to the documents in the company's archive.

The need to comprehensively document models and the relationship between model members in the family is vital in order to reduce inappropriate model use and enhance reuse.

\section{- A diversity of model forms}

There is a wide range of model forms from social, economic, human factors and technical models through to mechanistic, empirical, stochastic and deterministic models. Each has characteristics that create challenges for integration with underlying process models. It is often difficult to easily connect or embed such models. Some limited capabilities exist in several commercial systems but coupling, for example, operator behavioural models to dynamic process models for assessment of abnormal situation management strategies is not trivial. Other potential applications that are difficult to implement involve real time fault tree methods connected to process models. This inevitably means specialized software "bridges" are required for reliable connectivity. Far better connectivity is needed for current tools so that risk issues can be adequately addressed and the often circuitous routes taken by developers and users are avoided.

The development of these capabilities in modelling and simulation systems will be essential to wider collaborative efforts across the life cycle, otherwise modelling use is unnecessarily restrictive. This issue is also raised by Britt et al. (2004).

Exchanging models between different modelling environments such as gPROMS, Modelica or AspenPlus using a model exchange language like CapeML (v. Wedel 2002) provides a neutral exchange mechanism for model use across application packages. This was one part of the larger program of CAPE-OPEN and Global CAPEOPEN (COLAN 2004) that seeks to address mobility and exchange of modelling across diverse application platforms by setting open standard interfaces for computer aided 
engineering applications. It is confined mainly to the process modelling and simulation vendors.

\section{- A granularity in the model representations}

This relates to model enrichment or simplification across the life cycle. Typically this means increasing detail as the life cycle phase progresses chronologically. Risk management here requires the ability to develop, use and store a range of documented representations of the process as the life cycle progresses. A number of systems permit this activity. These include the Repository of a Modelling Environment (ROME) system (v. Wedel and Marquardt 2000) which enables neutral models to be stored in terms of fundamental modeling objects. The ROME system provides import and export capabilities for various application software. It thus provides a means of storing, retrieving and using models over the life cycle. The wider problem of handling model storage across organizations is still largely unaddressed and unsolved with ad hoc solutions prevailing.

\section{- A diversity of time and length scales}

This relates to the different phenomena being captured in the models, representing the multiscale nature of product and process engineering.

Despite a huge increase in interest in multiscale systems there is still no clear, unified approach to tackling such complex modelling problems. Issues such as model integration strategies across scales are starting to take shape (Pantelides 2001, Ingram et al. 2004). The fidelity and form of partial models to be included in multiscale representations is an active research area as are solution strategies which are non-trivial in nature. Current integration strategies are customized solutions with no general modelling and simulation tools that help develop, integrate and solve such applications. Given the growing importance of multiscale approaches, driven by genomic, biological, materials and particulate applications we face the risk that such important areas will suffer from long development times, poor selection of relevant scales and unacceptable solution times. There is much opportunity here for innovative methods to be developed.

\section{- A diversity of tools and players}

Related to accomplishing the modelling tasks there are still many diverse tools from standard flowsheeting packages to purpose-built models that are essentially standalone items in languages such as C, Fortran, Java or Matlab. In some cases, specific industrial models in many of the largest organizations have been developed in such environments as MS Excel, despite what purists might think! Non-existent documentation is common. In the area of risk assessment, specialized software systems for safety and environmental risk are typically used. The challenge here is in the effective use of such tools and the access to data, some in real time, for these applications. Much of the effort has been centred on data base technologies and specialized server architectures.

Tools integration remains a major challenge for life cycle modelling. The core activity of product and process engineering provides the backbone to many related activities. Several commercial systems such as gPROMS (2005) and ASPEN Suite (2005) provide a limited range of facilities to allow diverse tool use. 
Much of the life cycle modelling that is undertaken is independent in nature, typically performed by a range of external consultants, in-house company groups and government agencies. This diversity raises many risk management issues, such as generating dubious decision making since operational limits were never understood. Often modelling done external to the organization does not find its way into the corporate memory or archives. This can lead to serious problems when retrofits are undertaken, since much of the information is irretrievable. This happens particularly in quantified risk assessment (QRA) studies when major plant upgrades are made necessitating a complete reanalysis with little reuse of previous work - a major financial impost.

\section{- A diversity of data and documentation}

Data is at the heart of modelling and data representation is crucial to effective model development. Commercial systems like ASPEN Zyqad have sought to address such issues. Other conceptual developments such as the Conceptual Lifecycle model (CLiP) (Bayer 2003; Bayer et al. 2002; Schneider and Marquardt 2002), have investigated a framework in chemical engineering for design, model development and reuse.

The CLiP development, in theory, covers socio-technical systems but is yet to be expanded and developed to a point where it can adequately cover the range of industrial modeling activities common to major industrial developments.

The extension of the CLiP data model into an ontological representation, OntoCAPE (Yang et al. 2003), seeks to put these concepts in a form which can be used for reasoning about the domains covered by the concepts. This provides the possibility of building intelligent software agent systems that can help practitioners perform modeling and design tasks.

Data exchange in the area of process engineering has also been of major concern leading to such initiatives as the Process Data Exchange Institute (pDXi) which was initiated in 1989 by the American Institute of Chemical Engineers and numerous organizations within the USA and Europe. It appears that actual usage of the standard is very limited. Other initiatives such as the Standard for Exchange of Product Model Data (STEP) within the industrial automation and integration standard, ISO10303 could provide extensive specifications for chemical engineering related equipment, processes assembly and design (ISO 2004).

Documentation in a corporation is a major challenge, given the enormous amounts of reports, figures, drawings, memos, letters, consulting documents and the like that are generated throughout the process or product life cycle. A number of large commercial systems exist to address this issue, such as Documentum ${ }^{\text {TM }}$ (Documentum 2004), that provide enterprise content management (ECM). Recent developments provide collaborative workspaces that give facilities to share ideas and information within the corporation and beyond. Challenges still exist in being able to effectively link important documents to other technical systems such as hazard and risk registers or plant level systems, so that documents can be retrieved in a timely fashion for decision making purposes. 


\section{Conclusions}

Product and process life cycle concepts are now of prime importance to the corporate and regulatory sectors. Modelling underpins much of the business and technical decision making of a company and this decision making is driven mainly by considerations of socio-technical risks. This paper has shown the breadth of risk management tasks across the complete process life cycle. Many of the tasks are tackled through modelling and that modelling and the accompanying workflow has a wide range of characteristics which generate risks for modelling practice and decision making.

There have been significant developments in tools to aid in modelling and simulation. Due to the complexity of life cycle modelling, there are many significant challenges remaining. Those challenges relate to the handling of the growing multi- and interdisciplinary nature of modelling across the life cycle as well as risk management issues within the process modelling cycle.

There is still much to be done in terms of new methodologies and approaches to modelling, data handling, knowledge retention and use. Risk management demands that decisions are timely, well informed and focussed. Modelling plays a key role in these tasks and we need improved systems to deal with the challenges.

\section{References}

Anderson, J.S., 1966, Practical reactor problem in dynamic heat transfer, Chemical Engineering Science, n198, 97-103, (May).

ASPEN, 2005, Aspen Technology Inc., http://www.aspentech.com , Accessed January 2005.

Bañares-Alcantará, R. and H.M.S. Lababidi, 1995, Design support systems for process engineering, Computers and Chemical Engineering, 19, 267-301.

Bayer, B., 2003, Conceptual information modeling for computer aided support of chemical process design, PhD Thesis, Nr. 787, Lehrstuhl für Prozesstechnik, RWTH Aachen University, Germany, ISBN 3-18-378703-2.

Bayer, B., C. Krobb and W. Marquardt, 2002, A data model for design data in chemical engineering - information models, Tech Report LPT-2001-15, Lehrstuhl für Prozesstechnik, RWTH Aachen University, Germany.

Bogush, R., B. Lohmann and W. Marquardt, 1996, Computer-Aided Process Modeling with ModKit, Technical Report \#8, RWTH Aachen University of Technology.

Britt, H., Chen, C-C., Mahalec,V and A. McBrien, 2004, Modeling and Simulation in 2004: An industrial perspective, FOCPAD 2004 Proceedings Princeton, New Jersey, pp. 55-68, July.

Cameron, I.T. and R. Raman, 2005, Process Systems Risk Management, Volume 6 in Process Systems Engineering, Elsevier, NL.

Carson, Rachel L., 1962, Silent Spring, Houghton Miffin, Boston USA.

Chiles, J.R., 2001, Inviting disaster: Lessons from the edge of technology, Harper Business, New York, USA

COLAN, 2004, http://zann.informatik.rwth-aachen.de:8080/opencms/opencms/ COLANgamma/ index.html

Crichton, M., 2004, State of Fear, Harper Collins Publishers, London, U.K.

Documentum Inc., 2004, http://www.documentum.com., Accessed December 2004

Foss, B.A., B. Lohmann and W. Marquardt, 1988, A Field Study of the Industrial Modeling Process, Journal of Process Control, 8(5-6), 325-338. 
Gabbar, H.A. et al., 2001, Design of plant safety model in plant enterprise engineering environment, Reliability Engineering and System Safety 73, 35-47.

Gäbel, K. et al., 2004, The design and building of a life cycle based process model for simulating environmental performance, product performance and cost in cement manufacturing, Journal of Cleaner Production 12, 77-93.

gPROMS, 2005, General Process Modelling System, Process Systems Enterprise, London, http://www.psenterprise.com , Accessed January 2005.

Hangos, K.M. and I.T. Cameron, 2001, Process modelling and model analysis, Academic Press, London, ISBN 0-12-156931-4.

Hicks, D.L., B.D. Crittenden and A. Warhurst, 2000, Design for decommissioning: Addressing the future closure of chemical sites in the design of new plant, Trans.IChemE 78, Part B, 465479.

Hodgson, J., 2001, ADMET-turning chemicals into drugs, Nature Biotechnology 19, 722-726.

Ingram, G.D., Hangos, K.M. and I.T. Cameron, 2004 Classification and analysis of integrating frameworks in multiscale modeling, Chemical Engineering Science , 59 (11): 2171-2187

International Standards Organization (ISO), 2002, Systems Engineering - System Life Cycle Processes ISO/IEC 15288, October.

Kwak, Y.H. and K.S. LaPlace, 2005, Examining risk tolerance in project-driven organization, Technovation 25, 691-695.

Marquardt, W., L. von Wedel, L. and B. Bayer, 2000, Perspectives on Lifecycle Process Modelling, FOCAPD, $5^{\text {th }}$ International Conference on Computer-aided process design, AIChE Symposium Series 323, volume 96, 192-214.

McGahey, S. and I.T. Cameron, 2002, Transformations in Model Families, ESCAPE12, Computers \& Chemical Engineering, The Hague, The Netherlands.

Pantelides, C., 2001, New challenges and opportunities for process modelling, European Symposium on Computer Aided Process Engineering 11, 15-26.

Pantelides, C. and Z. Urban, 2004, Process Modelling Technology: A critical review of recent developments, FOCAPD 2004 Proceedings Princeton, New Jersey, pp. 69-82, July.

Perrow, C., 1999, Normal accidents: Living with high risk technologies, Princeton University Press, USA.

Pires, T.T., 2005, An approach for modelling human cognitive behaviour in evacuation models, Fire Safety Journal (in press).

Rawlins, M.D., 2004, Cutting the cost of drug development? Nature Reviews Drug Discovery 3, 360-364, April.

Rosselot, K.S. and D.T. Allen, Chapter 13: Life-Cycle Concepts, Product Stewardship, and Green Engineering in Green Engineering: Environmentally Conscious Design of Chemical Processes by D.T. Allen and D. Shonnard, Prentice Hall PTR, Upper Saddle River, et al., 2002.

Schneider, R. and W. Marquardt, 2002, Information technology support in the chemical process design lifecycle, Chemical Engineering Science 57(10), 1763-1792.

Searls, D.B., 2005, Data Integration: Challenges for drug discovery, Nature Reviews Drug Discovery 4, 45-58.

Standards Australia (SA), 2004, AS4369:2004 Risk Management, Standards Australia, Canberra

Stark, J., 2005, Product Lifecycle Management: $21^{\text {st }}$ Century Paradigm for Product Realisation, Springer, London.

Stephanopoulos, G. Henning, G. and H.Leone, 1990, Model.la a modeling language for process engineering, Computers and Chemical Engineering 8, 847-869.

Virkki-Hatakka, T., et al., 2003, Modelling at different stages of process life-cycle, European Symposium on Computer Aided Process Engineering (ESCAPE)-13, 977-982, Elsevier Science

v. Wedel, L., 2002, CapeML - A model exchange language for chemical process modelling, Tech Report LPT-2002-16, Lehrstuhl für Prozesstechnik, RWTH Aachen University, Germany. 
v. Wedel, L. and W. Marquardt, 2000, ROME: A Repository to Support the Integration of Models over the Lifecycle of Model-based Engineering Processes In: S. Pierucci (Ed.): European Symposium on Computer Aided Process Engineering 10, Elsevier, 2000, 535-540.

Williams, R.P.B., R. Keays, S. McGahey, I.T. Cameron, I.T. and K.M. Hangos, 2002, SCHEMA: An object oriented modeling language for continuous and hybrid process models, Asia Pacific Conference on Chemical Engineering (APCChE), Paper \#922, Christchurch, New Zealand.

Yang, A. et al., 2003, Principles and Informal Specification of OntoCAPE: COGENTS Project, Information Society Technologies (IST) Programme, IST-2001-34431, European Union. 
